Original Research

\title{
Pharmacokinetic Evaluations of Sulpiride After Intravenous, Intramuscular, and Oral Single-Dose Administration in Jennies (Equus asinus)
}

\author{
Mario Giorgi ChemD, MsPharmacol ${ }^{\mathrm{a}}$, Cecilia Vullo DVM, PhD ${ }^{\mathrm{b}}$, Virginia De Vito ChemD ${ }^{\mathrm{a}, *}$, \\ Giuseppe Catone DVM, PhD ${ }^{\mathrm{b}}$, Vanessa Faillace DVM ${ }^{\mathrm{b}}$, Fulvio Laus DVM ${ }^{\mathrm{b}}$ \\ a Department of Veterinary Sciences, University of Pisa, Pisa, Italy \\ ${ }^{\mathrm{b}}$ School of Biosciences and Veterinary Medicine, University of Camerino, Matelica, Macerata, Italy
}

\section{A R T I C L E I N F O}

\section{Article history:}

Received 27 August 2014

Received in revised form 30 September 2014

Accepted 28 October 2014

Available online $\mathrm{xxxx}$

\section{Keywords:}

Sulpiride

Pharmacokinetics

Donkey

Bioavailability

\begin{abstract}
A B S T R A C T
Sulpiride is an antipsychotic human drug. It is commonly used to encourage ovulation in noncycling mares and to stimulate lactation in adoptive mares. No pharmacokinetic data are available for donkeys. The aim of this study was to assess the pharmacokinetics profile of sulpiride after intravenous (IV), intramuscular (IM), and oral (PO) administrations in healthy jennies. Animals $(\mathrm{n}=6)$ were treated with sulpiride, $1 \mathrm{mg} / \mathrm{kg}$ by IV, IM, and PO routes according to a randomized cross-over design $(3 \times 3$ Latin square). Blood samples $(5 \mathrm{~mL})$ were collected at predetermined times and analyzed using a validated high performance liquid chromatography with fluorescence detection method. IV and IM administrations gave similar curves, but they were not bioequivalent. The IM average bioavailability was $73.5 \%$. After PO administration, the drug plasma concentrations were low and consequently both area under the curve and bioavailability (9.4\%) were low. This finding could be because of the physicochemical features of the drug. Indeed, considering that sulpiride is a weak base, existing in the ionized form at gastric and physiological $\mathrm{pH}$, it is unsurprising that it is poorly absorbable, especially in equine species whose gastric $\mathrm{pH}$ is particularly acidic. In conclusion, injective routes are definitely preferable to PO dosing because of the very low F\% via this route.
\end{abstract}

(c) 2014 Elsevier Inc. All rights reserved.

\section{Introduction}

Sulpiride (SLP) belongs to a special class of antipsychotic drugs, the substituted benzamides. These possess a more specific pharmacologic profile than the conventional neuroleptics. SLP selectively blocks the peripheral and central dopamine (D2 subtype) receptors, whereas the interaction with the D1 subtype is negligible. Probably, SLP does not interact with noradrenergic or

\footnotetext{
* Corresponding author at: Virginia De Vito, ChemD, Department of Veterinary Sciences, University of Pisa, Via Livornese (lato monte), San Piero a Grado, 56122 Pisa, Italy.

E-mail address: virgidevit@libero.it (V. De Vito).
}

serotonergic receptor mechanisms. Sulpiride is widely used in humans as a behavior regulator to treat mental disorders and for the psychopathology of senescence, depression, and schizophrenia. The daily dose for these indications is $200-800 \mathrm{mg}$ [1]. It is also used at doses of 50-150 mg per human for the treatment of gastric or duodenal ulcers [2], in the treatment of an irritable colon due to psychosomatic stress [3], and in various vertigo syndromes [4]. Tolerance to SLP at this lower dosage is very good, and extrapyramidal, neurovegetative, and endocrine side effects are rare [5].

The earliest application of this molecule in equine reproduction was to treat fescue toxicosis $(3.3 \mathrm{mg} / \mathrm{kg}$ ): in this application, a stimulation of endogenous prolactin 
level and/or induction of galactopoiesis in agalactic mares was observed [6]. In subsequent studies, SLP has been used to induce lactation in cycling and noncycling mares (0.5$1 \mathrm{mg} / \mathrm{kg}$ twice a day) [7] or to hasten the first ovulation of the breeding season in noncycling mares $(1 \mathrm{mg} / \mathrm{kg}$ once a day) [8-11].

Although the effectiveness of SLP in transitional mares is still controversial $[8,11]$, SLP is used in equine practice. Recently, a pharmacokinetic (PK) study has described its disposition in horses [12]. Determining a rational dosing regimen is a long and complicated endeavor because of differences in the expression of enzymes, receptors, and signal transduction molecules between species. Both interand intra-species differences in drug response can be accounted for as either being because of variations in drug PK or drug pharmacodynamics; the magnitude and relative contribution of each of these varies from drug to drug. In addition, although animal species may be morphologically similar, they can still have considerable differences in their response to drugs. Optimization of treatment with SLP initially requires knowledge of its bioavailability, PK, and metabolism in the target species. The PK parameters determined after a single-dose administration can then be used for dosage regimen adjustments and individualization of therapy. In addition, donkey might be of particular interest because of its milk. Indeed, the global market is asking for an increased production of donkey milk for its excellent nutritive features [13]. Hence, the aim of this study was to assess the PK profile of SLP after intravenous (IV), intramuscular (IM), and oral (PO) administrations in healthy jennies.

\section{Materials and Methods}

\subsection{Animal Treatments and Sampling}

Six nurse jennies, aged 7-12 years and weighing 190$250 \mathrm{~kg}$, were used. The jennies were previously determined to be clinically healthy based on a physical examination and full chemistry and hematological analyses. Animal experiments were conducted at the Veterinary Teaching Hospital, School of Biosciences and Veterinary Medicine (University of Camerino). Animal care and handling were performed according to the provision of the EC council Directive 86/ 609 EEC. The study protocol was approved by the University of Camerino's Ethics Committee for animal welfare and transmitted to the Italian Ministry of Health (authorization number 11/2014). Animals were randomly assigned to three treatment groups, using an open, single-dose, threetreatment, three-period, paired, randomized cross-over design ( $3 \times 3$ Latin square). Each subject in group I $(\mathrm{n}=$ 2) received a single dose of $1 \mathrm{mg} / \mathrm{kg}$ of SLP (Championyl, Sanofi Aventis, France) injected IV over 1 minute into the left jugular vein, in the morning after fasting for 12 hours overnight. Animals in group II $(n=2)$ received the same dose but by IM route, injected in the middle quadrant of the neck muscle, after fasting for 12 hours overnight. Animals in group III $(n=2)$, after overnight fasting, received the same dose via nasogastric tube. For this route, tablets of SLP were used (Championyl 50 mg/tablet Sanofi Aventis). After administration, the nasogastric tube was rinsed with
$300 \mathrm{~mL}$ of distilled water to ensure complete delivery of the drug into the stomach. A catheter was placed into the right jugular vein to facilitate blood sampling. The washout period was 1 week. The groups were rotated and the administrations repeated. After 3 weeks, each donkey had been administered with SLP by the three routes. Blood samples $(5 \mathrm{~mL})$ were collected at $0,5,15,30$, and $45 \mathrm{mi}-$ nutes and $1,1.5,2,4,6,8,10,24$, and 34 hours after administration of SLP and placed in collection tubes containing lithium heparin. The blood samples were centrifuged at 3,000 $\times g$ within 30 minutes of collection, and the harvested plasma was stored at $-20^{\circ} \mathrm{C}$ until use within 30 days of collection.

\subsection{Chemicals and Reagents}

Pure powders of SLP ( $>99.0 \%$ purity) and metoclopramide (internal standard [IS]) were sourced from Sigma-Aldrich (St. Louis, MO). High performance liquid chromatography (HPLC) grade acetonitrile (ACN), ethyl acetate (EtAc), methanol $(\mathrm{MeOH})$, and methylene chloride $\left(\mathrm{CH}_{2} \mathrm{Cl}_{2}\right)$ were purchased from Merck (Darmstadt, Germany). Analytical grade sodium hydroxide $(\mathrm{NaOH})$, acetic acid $(\mathrm{AcOH})$, and ammonium acetate $\left(\mathrm{AcONH}_{4}\right)$ were purchased from Carlo Erba (Milan, Italy). Deionized water was produced by a Milli-Q Millipore Water System (Millipore, MA). All the other reagents and materials were of analytical grade and supplied from commercial sources. The aqueous and organic components of the mobile phase, degassed under pressure, were mixed by the HPLC. The liquid chromatography mobile phases were filtered through $0.2-\mu \mathrm{m}$ cellulose acetate membrane filters (Sartorius Stedim Biotech, Aubagne Cedex) with a solvent filtration apparatus.

\subsection{Preparation of Solutions}

Singular stock solutions of SLP and IS in $\mathrm{MeOH}$ were prepared at an individual concentration of $1,000 \mu \mathrm{g} / \mathrm{mL}$ using volumetric flasks; these were stored at $-20^{\circ} \mathrm{C}$. To reach a final concentration of $100 \mu \mathrm{g} / \mathrm{mL}$, appropriate dilutions of stock standard solutions were prepared, diluting $1 \mathrm{~mL}$ of each solution to $10 \mathrm{~mL}$. Successively, these solutions of SLP and IS were diluted in glass tubes $(10 \mathrm{~mL})$ to reach final concentrations of 10,5 , and $1 \mu \mathrm{g} / \mathrm{mL}$. These were stored at $-20^{\circ} \mathrm{C}$. This latter concentration $(1 \mu \mathrm{g} / \mathrm{mL})$ was then diluted with $\mathrm{MeOH}$ to prepare a five-point calibration curve of the analytes at the following concentrations: $0.200,0.100,0.050,0.025,0.010$, and $0.001 \mu \mathrm{g} / \mathrm{mL}$. The two analytes were stable for at least 30 weeks if stored at $-20^{\circ} \mathrm{C}$.

\subsection{Instrumentation and Chromatographic Conditions}

The HPLC system was an LC system (Jasco, Japan) consisting of a high pressure mixer pump (model PU 980 Plus), spectrofluorometric detector (model 2020 Plus), and a loop of $50 \mu \mathrm{L}$. Data were processed by Borwin software (Jasco, Inc.). Chromatographic separation assay was performed by a Luna C18 ODS2 analytical column $(150 \times 4.6 \mathrm{~mm}$ inner diameter, $5-\mu \mathrm{m}$ particle size, Phenomenex, Torrance, CA) 
maintained at $25^{\circ} \mathrm{C}$. The mobile phase consisted of $\mathrm{ACN}$ :buffer $\left(10 \mathrm{mM} \mathrm{AcONH}_{4}\right.$, adjusted to $\mathrm{pH} 5.2$ with $\mathrm{AcOH}$; $15: 85 \mathrm{vol} / \mathrm{vol} \%$ ) at a flow rate of $1.2 \mathrm{~mL} / \mathrm{min}$. Excitation and emission wavelengths were set at 300 and $356 \mathrm{~nm}$, respectively.

\subsection{Sample Extraction}

The procedure was based on a previously reported method [12]. Briefly, in a 15-mL screw cap polypropylene vial, a $1-\mathrm{mL}$ aliquot of plasma sample was added to $100 \mu \mathrm{L}$ of IS $(0.25 \mu \mathrm{g} / \mathrm{mL})$. After 30 -second vortexing, $0.1 \mathrm{~mL}$ of $\mathrm{NaOH}(1 \mathrm{M})$ was added and the sample vortexed again. An aliquot of $6 \mathrm{~mL}$ of EtAc: $\mathrm{CH}_{2} \mathrm{Cl}_{2}(5: 1, \mathrm{vol} / \mathrm{vol})$ was added, then vortexed (30 seconds), shaken (60 osc/min, $10 \mathrm{mi}-$ nutes) and centrifuged at $10,956 \times g$ for 10 minutes at $10^{\circ} \mathrm{C}$. The supernatant was collected in a new $15-\mathrm{mL}$ screw cap vial. The organic phase was evaporated under a gentle stream of nitrogen $\left(40^{\circ} \mathrm{C}\right)$ and reconstituted with $200 \mu \mathrm{L}$ of mobile phase. Fifty microliters of this solution was injected onto the HPLC with fluorescence detector.

\subsection{Quantification}

The calibration curve of peak area versus concentration $(\mathrm{ng} / \mathrm{mL})$ of SLP was plotted. Least squares regression parameters for the calibration curve were calculated, and the concentrations of the test samples were interpolated from the regression parameters. Sample concentrations were determined by linear regression, using the formula $\mathrm{Y}=\mathrm{mX}$ $+\mathrm{b}$, where $\mathrm{Y}=$ peak area, $\mathrm{X}=$ concentration of the standard in $\mathrm{ng} / \mathrm{mL}, \mathrm{m}=$ the slope of the curve, and $\mathrm{b}=$ the intercept with Y axis. Correlation coefficients for each of the calibration curves were $>0.99$.

When unknown samples were assayed, a control and a fortified blank sample were processed simultaneously for quality control. Limit of detection (LOD) and limit of quantification (LOQ) were determined as analyte concentrations giving signal-to-noise ratios of 3 and 10, respectively. Limit of quantification was $1 \mathrm{ng} / \mathrm{mL}$, and LOD was
$5 \mathrm{ng} / \mathrm{mL}$. The values of precision for SLP were always lower or equal to 5.4 (coefficient of variability\%), whereas accuracy was less than $6.3 \%$.

\subsection{PK Analysis}

The PK calculations were carried out using WinNonLin version 5.3.1 (Pharsight Corp). The exponential parameters, in addition to the error model parameters, were estimated [14]. Sulpiride plasma concentrations versus time curves were modeled for each subject using a monocompartment or a two-compartment open model. Comparison between competing models was made using the Akaike test.

Maximum concentration $\left(C_{\max }\right)$ of SLP in plasma and the time required to reach $C_{\max }\left(T_{\max }\right.$ ) were predicted from the data. The area under the concentration versus time curve $\left(\mathrm{AUC}_{0-\infty}\right)$ was calculated using the linear trapezoidal rule. Intramuscular or PO bioavailability (F\%) was calculated from the ratio of the areas under the plasma SLP concentration curve after IM, PO, and IV administrations, indexed to their respective dose:

$\mathrm{F}(\%)=\left(\mathrm{AUC}_{\mathrm{IM} \text { or } \mathrm{PO}} \times\right.$ Dose $\left._{\mathrm{IV}}\right) /\left(\mathrm{AUC}_{\mathrm{IV}} \times\right.$ Dose $\left._{\mathrm{IM} \text { or PO }}\right) \times 100$

The compartmental PK variables absorption rate $\left(\mathrm{K}_{01}\right)$, elimination rate from compartment $1\left(K_{10}\right)$, rate of movement from compartment 1 to $2\left(\mathrm{~K}_{12}\right)$, the rate of movement from compartment 2 to $1\left(K_{21}\right)$, half-life of distribution phase (HL alpha), half-life of the elimination phase (HL beta), clearance (CL), and volume of distribution (VD) are presented in Table 1.

\subsection{Statistical Analysis}

To make comparisons across treatments, the different parameters were first tested for normal distribution and variance homogeneity. This was achieved by performing a two-way analysis of variance on the randomized $3 \times 3$ Latin square design.

Table 1

Main (two-compartment model) pharmacokinetic parameters of sulpiride (SLP) after intravenous (IV), intramuscular (IM), and oral (PO) administrations of SLP $(1 \mathrm{mg} / \mathrm{kg})$ in jennies.

\begin{tabular}{|c|c|c|c|}
\hline Parameters & IV $(n=6)$ & $\operatorname{IM}(\mathrm{n}=5)$ & $\mathrm{PO}(\mathrm{n}=4)$ \\
\hline$R^{2}$ & $0.99 \pm 0.01$ & $0.99 \pm 0.01$ & $0.97 \pm 0.03$ \\
\hline $\mathrm{AUC}_{0-\infty}(\mathrm{ng} \mathrm{hr} / \mathrm{mL})$ & $7,935.03 \pm 1,127.20$ & $6,263.54 \pm 946.40$ & $617.89 \pm 48.04$ \\
\hline $\mathrm{CL}(\mathrm{mL} / \mathrm{hr} / \mathrm{kg})$ & $133.81 \pm 37.62$ & $165.77 \pm 33.05$ & $1,618.41 \pm 68.63$ \\
\hline $\mathrm{VD}(\mathrm{mL} / \mathrm{kg})$ & $410.46 \pm 93.47$ & $411.95 \pm 86.36$ & $87.10 \pm 14.89$ \\
\hline HL alpha (hr) & $0.24 \pm 0.09$ & $0.40 \pm 0.23$ & $0.96 \pm 0.01$ \\
\hline HL beta (hr) & $4.24 \pm 0.84$ & $3.87 \pm 0.85$ & $2.89 \pm 0.95$ \\
\hline $\mathrm{K}_{10}(1 / \mathrm{hr})$ & $1.03 \pm 0.22$ & $0.45 \pm 0.23$ & $0.71 \pm 0.01$ \\
\hline $\mathrm{K}_{12}(1 / \mathrm{hr})$ & $1.78 \pm 0.88$ & $1.35 \pm 0.56$ & $0.01 \pm 0.003$ \\
\hline $\mathrm{K}_{21}(1 / \mathrm{hr})$ & $0.65 \pm 0.21$ & $1.04 \pm 0.27$ & $0.24 \pm 0.04$ \\
\hline $\mathrm{K}_{01}(1 / \mathrm{hr})$ & & $8.12 \pm 1.36$ & $0.75 \pm 0.01$ \\
\hline$T_{\max }(\mathrm{hr})$ & & $0.32 \pm 0.09$ & $1.37 \pm 0.47$ \\
\hline$C_{\max }(\mathrm{ng} / \mathrm{mL})$ & & $1,534.55 \pm 68.11$ & $164.55 \pm 22.92$ \\
\hline $\mathrm{F} \%$ & & $73.5 \pm 7.2$ & $9.4 \pm 5.9$ \\
\hline
\end{tabular}

Abbreviations: $\mathrm{AUC}_{0-\infty}$, area under the plasma concentration-time curve extrapolated to infinity; $\mathrm{CL}$, clearance; $C_{\mathrm{max}}$, peak plasma concentration; F\%, absolute bioavailability; HL alpha, distribution half-life; HL beta, disposition half-life; $\mathrm{K}_{01}$, absorption rate constant; $\mathrm{K}_{10}$, elimination rate constant; $\mathrm{K}_{12}$, distribution in peripheral tissues rate constant; $\mathrm{K}_{21}$, transfer rate constant from tissue to plasma; $R^{2}$, correlation coefficient; $T_{\text {max }}$, time of peak; VD, volume of distribution. 


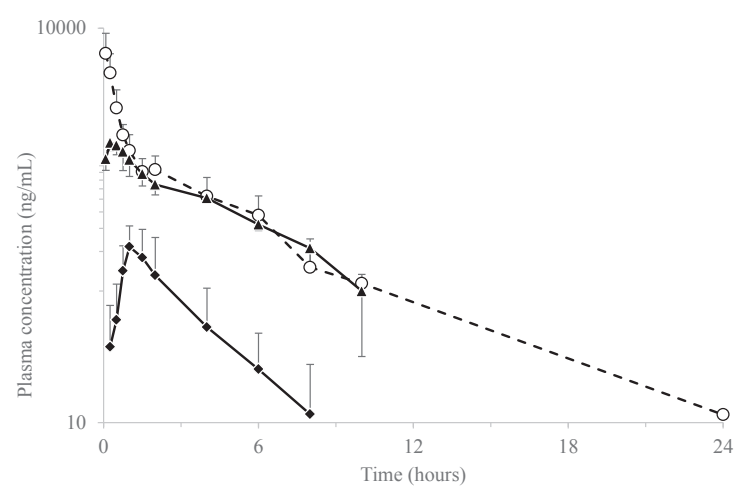

Fig. 1. Observed mean plasma concentrations of sulpiride (SLP) after IV $\left(--_{-}, \mathrm{n}=6\right)$, IM $(-\Delta-, \mathrm{n}=6)$, and PO $(-\bullet-, \mathrm{n}=6)$ administrations of SLP $(1 \mathrm{mg} / \mathrm{kg})$ in jennies. Bars represent standard deviation of the mean.

\section{Results}

Sulpiride administrations at $1 \mathrm{mg} / \mathrm{kg}$ via IV, IM, and PO routes were well tolerated. This dose was chosen according to recent studies assessing the effectiveness of SLP when administered daily for a 21-day period $[9,10]$ and the PK profile after a single-dose administration in horses [12]. No adverse effects were observed during the present study.

The mean concentration versus time curves of the three treatments are reported in Fig. 1.

\subsection{Administration}

After IV administration, all concentration versus time curves were analyzed systematically using the extended least squares regression analysis, according to a monocompartment or a two-compartment body model. Statistical analysis of the fit of model to the curves indicated that the data sets were consistent with a two-compartment body model. Monocompartment model was also able to

\section{Table 2}

Main (monocompartment model) pharmacokinetic parameters of sulpiride (SLP) after intramuscular (IM) administration of SLP $(1 \mathrm{mg} / \mathrm{kg})$ in a jenny.

\begin{tabular}{lr}
\hline Parameters & IM $(\mathrm{n}=1)$ \\
\hline$R^{2}$ & 0.97 \\
AUC $_{0-\infty}(\mathrm{ng} \mathrm{hr} / \mathrm{mL})$ & $4,040.21$ \\
$\mathrm{~K}_{01}(1 / \mathrm{hr})$ & 16.25 \\
$\mathrm{~K}_{10}(1 / \mathrm{hr})$ & 0.32 \\
$\mathrm{HL}$ alpha $(\mathrm{hr})$ & 0.04 \\
$\mathrm{HL}$ beta $(\mathrm{hr})$ & 2.16 \\
$\mathrm{CL}(\mathrm{mL} / \mathrm{hr} / \mathrm{kg})$ & 247.51 \\
$\mathrm{VD}(\mathrm{mL} / \mathrm{kg})$ & 771.41 \\
$T_{\max }(\mathrm{hr})$ & 0.25 \\
$C_{\max }(\mathrm{ng} / \mathrm{mL})$ & $1,197.79$ \\
$\mathrm{~F} \%$ & 75.21 \\
\hline
\end{tabular}

Abbreviations: $\mathrm{AUC}_{0-\infty}$, area under the plasma concentration-time curve extrapolated to infinity; $\mathrm{CL}$, clearance; $C_{\max }$, peak plasma concentration; F\%, absolute bioavailability; $\mathrm{HL}$ alpha, distribution half-life; $\mathrm{HL}$ beta, disposition half-life; $\mathrm{K}_{01}$, absorption rate constant; $\mathrm{K}_{10}$, elimination rate constant; $R^{2}$, correlation coefficient; $T_{\max }$, time of peak; VD, volume of distribution. fit the curves in three cases of the six, but the Akaike coefficient was greater than that in the two-compartment body model fitting. Sulpiride was detectable up to 8, 10, and 24 hours in one, four, and one subject, respectively, and had dropped below the LOD of the method at 34 hours. Distribution in peripheral tissues was rapid $\left(\mathrm{K}_{12}=1.781\right.$ / $\mathrm{hr})$, with a transfer rate constant from tissue to plasma $\left(\mathrm{K}_{21}\right)$ that was almost half the elimination rate constant $\left(K_{10}\right)$. The average half-life of elimination was 4.24 hours; the CL and VD were fast and wide, respectively. The full PK parameters are reported in Table 1.

\subsection{IM Administration}

After IM administration, data were consistent with a two-compartment body model for five subjects. Data set from one animal was consistent with a monocompartment body model (Table 2). The plasma concentrations of SLP were detectable from 5 minutes to 10 hours in all the animals. Sulpiride showed a short $T_{\max }(0.32$ hours $)$ and fast distribution half-life ( 0.40 hours $)$ for the twocompartmental model, whereas these latter values were shorter (0.04 hours) in the monocompartment data set. The $C_{\max }$ values were quite similar within the range 1,197$1,534 \mathrm{ng} / \mathrm{mL}$. The average value for F\% after IM administration was $73.5 \pm 7.2$. The average CL value was greater than that found after IV administration, but if corrected for the $\mathrm{F} \%$, the difference was no longer significant $(P=.56)$. The mean half-life of elimination was 3.87 hours. The transfer rate constant from tissue to plasma $\left(K_{21}\right)$ was similar to the rate of distribution in peripheral tissues $\left(K_{12}\right)$. The full PK parameters are reported in Table 1.

\subsection{PO Administration}

After PO administration, large variability in plasma concentrations was found among the subjects. The plasma concentrations of SLP were detectable from $15(n=4), 30$ $(\mathrm{n}=1)$, or 45 minutes $(\mathrm{n}=1)$ to $2(\mathrm{n}=1), 4(\mathrm{n}=2)$, or 8 hours $(\mathrm{n}=4)$. A two-compartment open-model first-order absorption was the best fit for four data sets. Two data sets were not possible to be fit with any compartmental analysis. A noncompartmental analysis was also impossible because the elimination part of the curve got less than three points. The plasma concentrations of the drug were lower $(P<.05)$ than those at the corresponding time points for the other routes of administration. In addition, drug absorption was slowest for the PO route $(P<.01)$, with a $T_{\max }$ of 1.37 hours. $A \mathrm{CC}_{0-\infty}$ was small and consequently the PO F\% was $9.4 \pm 5.9$. These findings should be considered with the caveat that because of their large variability, they have limited value for predicting clinical behavior. A larger sample size of animals is warranted. The full PK parameters are reported in Table 1 .

\section{Discussion}

Several studies have been conducted in humans after IV, IM, and PO administrations of SLP [15-18]. The clinical dose administered to humans [1] is greater than the dose used in equine species because the desired effect is different (treat 
mental disorder vs. stimulate ovulation and/or lactation) and for allometric reasons [19]. The lack of adverse effects in jennies given $1 \mathrm{mg} / \mathrm{kg}$ concurs with a previous study in nurse mares [12] and with the good tolerance previously reported in human beings [5]. This also supports clinical reports showing no adverse effects in horses after a 3-week treatment period with this dose regimen [10]. Of relevance however, is the fact that SLP probably does not bind to plasma proteins [20], and it is likely to be predominantly excreted by the kidneys, mainly by glomerular filtration [15]. Hence, precautions should be taken in patients with impaired renal function, where the elimination half-life could be prolonged, whereas the cumulative amount excreted in the urine and the total and the renal clearances would be reduced [21]. This should be considered of particular importance in donkeys where the SLP CL has been found to be greater than that reported in horses [12].

It is important to note that SLP does not bind to red blood cells [17]. This might mean that the plasma concentration of SLP directly reflects the magnitude of clinical responses. Hence, SLP can be directly assayed in plasma for drug monitoring or dosage regimen optimization.

After IV and IM administrations, data sets were mainly consistent with a two-compartment model. This concurs with some previous horse [12] and human studies [17]; however, it is in disagreement with others [16]. The HL beta value was not statistically different between IV and IM administrations, a finding supported by horse [12] and human $[16,17]$ data. The IM F\% was $73.5 \%$; this is not in line with some previous data in horses where bioequivalence between IV and IM administrations was reported [12]. This fit with the well-documented PK differences between donkeys and horses [22]. The donkey therefore should not be regarded as a small odd-looking horse but should be recognized and treated as a species in its own right.

After PO administration, SLP absorption was relatively slow, with very large variations among individuals in the rate and the extent of absorption. These phenomena have been previously reported in horses [12]. The PO F\% of SLP is quite low in both humans (approximately 35\%) [18] and horses (20.4\%) [12], and the PO F\% reported in this study was even lower. The low PO F\% in equids compared with that in humans could be the result of physicochemical features of SLP. Indeed, considering that SLP is a weak base, existing in the ionized form at gastric and physiological $\mathrm{pH}$, it is unsurprising that it is poorly absorbable, especially in horses whose environmental $\mathrm{pH}$ is relatively acidic. However, the overnight fasting could have negatively affected the drug absorption, causing dramatic reduction in the gastric $\mathrm{pH}$ compared with fed animals.

Many physiological features of donkeys are different from those of horses. For example, plasma volume is maintained in dehydrated donkeys even when they lose $20 \%$ of normal body water, whereas horses are, by far, less resistant to this challenge [23]. Donkeys also appear to possess an increased metabolic capacity for certain drugs, which may be related to differences in cytochrome P450 isoenzymes [24]. Some of these differences might explain the dissimilarity in PO F\%. In addition, some recent studies have confirmed that the IM and PO F\% of drugs may vary drastically between horses [25] and donkeys [26].

Clearance after IV and IM administrations was 133.81 and $165.77 \mathrm{~mL} / \mathrm{hr} / \mathrm{kg}$, respectively; these are greater than the reported value for horses [12]. The greater CL in donkey compared with horses has also been previously proven $[25,26]$.

An earlier metabolic study reported four different metabolic reactions of SLP in the liver; these vary in importance for different animal species [27]. However, the unmetabolized drug was found to be predominant in all the tested species (with about $90 \%$ of an IV dose recovered unchanged in the urine [17]), indicating not only that a limited role in reducing the systemic availability of SLP can be attributed to the liver but also and of greater importance that the pharmacologic properties of SLP can be essentially attributed to the unchanged agent [27]. If a similar metabolic pattern is assumed for donkeys, it might be hypothesized that SLP will not accumulate substantially when given at $1 \mathrm{mg} / \mathrm{kg} / \mathrm{d}$ for several days of therapy. Indeed, the plasma concentration after 10 hours is very close to the LOQ and SLP is known to not affect (inhibit) the metabolism [27]. A recent study has successfully proposed an in situ forming gel-like depot of a polyaspartamide-polylactide copolymer for once a week administration of SLP in rabbits [28]. If this gel also proved to have application in equine species, it would offer a number of potential advantages. First, it could ensure that the titration schedule is simpler and easier to manage because of the reduction in dosing frequency (once a week), with better tolerance and increased compliance for both owners and animals. Second, the likelihood of adverse effects due to abrupt peaks in plasma concentrations and lack of effectiveness (due to rapidly decreasing post-peak plasma concentrations) is reduced because of the uniformity of SLP plasma concentrations. Further specific studies are needed to clarify this issue.

\section{Conclusions}

In the present study, IM and IV administrations have been shown to be similar but not bioequivalent. These routes are definitely preferable to PO dosing because of its very low F\%. Although a single daily administration at $1 \mathrm{mg} /$ $\mathrm{kg}$ is used in clinical practice, a sustained release formulation would be preferred to considerably reduce the labor, and from the PK point of view, avoid the abrupt high peaks in plasma concentrations, giving a better uniformity to SLP plasma concentrations.

\section{Acknowledgments}

None of the authors has any financial or personal relationships that could inappropriately influence or bias the content of the article. This work was supported by Athenaeum funds (ex 60\%) from the University of Pisa. The authors thank Dr. H. Owen (University of Queensland) for her critical evaluation of the article and for the invaluable English editing process. 


\section{References}

[1] Rzewuska M. Sulpiride: the best known atypical, safe neuroleptic drug. Review of literature. Psychiatr Pol 1998;32:655-66.

[2] Desai JK, Parmar NS. Gastric and duodenal anti-ulcer activity of sulpiride, a dopamine D2 receptor antagonist, in rats. Agents Actions 1994;42:149-53.

[3] Lanfranchi GA, Bazzocchi G, Marzio L, Campieri M, Brignola C. Inhibition of postprandial colonic motility by sulpiride in patients with irritable colon. Eur J Clin Pharmacol 1983;24:769-72.

[4] Zanetti D, Civiero N, Balzanelli C, Tonini M, Antonelli AR. Improvement of vestibular compensation by Levo-sulpiride in acute unilateral labyrinthine dysfunction. Acta Otorhinolaryngol Ital 2004;24: 49-57.

[5] Mauri MC, Bravin S, Bitetto A, Rudelli R, Invernizzi G. A risk-benefit assessment of sulpiride in the treatment of schizophrenia. Drug Saf 1996;14:288-98.

[6] Redmond LM, Cross DL, Strickland JR, Kennedy SW. Efficacy of domperidone and sulpiride as treatments for fescue toxicosis in horses. Am J Vet Res 1994;55:722-9.

[7] Guillaume D, Chavatte-Palmer P, Combarnous Y, Duchamp G, Martinat N, Nagy P, Daels PF. Induced lactation with a dopamine antagonist in mares: different responses between ovariectomized and intact mares. Reprod Domest Anim 2003;38:394-400.

[8] Duchamp G, Daels PF. Combined effect of sulpiride and light treatment on the onset of cyclicity in anestrous mares. Theriogenology 2002;58:599-602.

[9] Mari G, Morganti M, Merlo B, Castagnetti C, Parmeggiani F, Govoni N, Galeati G, Tamanini C. Administration of sulpiride or domperidone for advancing the first ovulation in deep anestrous mares. Theriogenology 2009;71:959-65.

[10] Panzani D, Zicchino I, Taras A, Marmorini P, Crisci A, Rota A, Camillo F. Clinical use of dopamine antagonist sulpiride to advance first ovulation in transitional mares. Theriogenology 2011;75:138-43.

[11] Daels PF, Fatone S, Hansen BS, Concannon PW. Dopamine antagonist-induced reproductive function in anoestrous mares: gonadotrophin secretion and effects of environmental cues. J Reprod Fertil 2000;56:173-83.

[12] Giorgi M, Ozdemir M, Camillo F, Panzani D. Pharmacokinetics of sulpiride after intravenous, intramuscular, and oral single-dose administration in nurse mares. J Equine Vet Sci 2013;33:533-8.

[13] Jirillo F, Jirillo E, Magrone T. Donkey's and goat's milk consumption and benefits to human health with special reference to the inflammatory status. Curr Pharm Des 2010;16:859-63.
[14] Gibaldi M, Perrier D. Pharmacokinetics. 2nd ed. New York: Dekker; 1982.

[15] Bressolle F, Bres J, Blanchin MD, Gomeni R. Sulpiride pharmacokinetics in humans after intramuscular administration at three dose levels. J Pharm Sci 1984;73:1128-36.

[16] Wiesel FA, Alfredsson G, Ehrnebo M, Sedvall G. The pharmacokinetics of intravenous and oral sulpiride in healthy human subjects. Eur J Clin Pharmacol 1980;17:385-91.

[17] Brès J, Bressolle F. Pharmacokinetics of sulpiride in humans after intravenous and intramuscular administrations. J Pharm Sci 1991; 80:1119-24.

[18] Bressolle F, Brès J, Fauré-Jeantis A. Absolute bioavailability, rate of absorption, and dose proportionality of sulpiride in humans. J Pharm Sci 1992;81:26-32.

[19] Hunter RP. Interspecies allometric scaling. In: Comparative and veterinary pharmacology. Cunningham, F., Elliott, J., Lees, P., (eds). Springer London UK, 2010 pp 140-155

[20] Alam AS, Imondi AR, Udinsky J, Hagerman LM. Bioavailability of 14C-sulpiride in dogs. Arch Int Pharmacodyn Ther 1979;242:4-13.

[21] Bressolle F, Bres J, Mourad G. Pharmacokinetics of sulpiride after intravenous administration in patients with impaired renal function. Clin Pharmacokinet 1989;17:367-73.

[22] Lizarraga I, Sumano H, Brumbaugh GW. Pharmacological and pharmacokinetic differences between donkeys and horses. Equine Vet Educ 2004;16:102-12.

[23] Matthews NS, Taylor TS, Hartsfield SM. Anaesthesia of donkeys and mules. Equine Vet Educ 1997;9:198-202.

[24] Peck K, Mealey KL, Matthews NS, Taylor TS. Comparative pharmacokinetics of caffeine and three metabolites in clinically normal horses and donkeys. Am J Vet Res 1997;58:881-4.

[25] Kim T, Della Rocca G, Di Salvo A, Ryschanova R, Micaela S, Giorgi M. Evaluation of pharmacokinetic and pharmacodynamic properties of cimicoxib in fasted and fed horses. N Z Vet J 2014. http://dx.doi.org/ 10.1080/00480169.2014.950355. in press.

[26] Kim T-W, Della Rocca G, Di Salvo A, Owen H, Sgorbini M, Giorgi M Pharmacokinetics of the novel cyclooxygenase 2 inhibitor cimicoxib in donkeys. J Equine Vet Sci 2014;34:923-5.

[27] Sugnaux FR, Benakis A. Metabolism of sulpiride: determination of the chemical structure of its metabolites in rat, dog and man. Eur J Drug Metab Pharmacokinet 1978;3:235-48.

[28] Fiorica C, Palumbo FS, Pitarresi G, Giorgi M, Calascibetta F, Giammona G. In situ forming gel like depot of a polyaspartamidepolylactide copolymer for once a week administration of sulpiride. J Pharm Pharmacol 2014. http://dx.doi.org/10.1111/jphp.12323. in press. 